\title{
Liver $X$ receptor inhibition potentiates mitotane-induced adrenotoxicity in ACC
}

\author{
Kate M Warde1, Erik Schoenmakers², Eduardo Ribes Martinez1, Yi Jan Lim1, Maeve Leonard1, Sarah J Lawless, \\ Paula O'Shea ${ }^{3}$, Krishna V Chatterjee ${ }^{2}$, Mark Gurnell ${ }^{2}$, Constanze Hantel ${ }^{4,5}$ and Michael Conall Dennedy ${ }^{1}$
}

1Discipline of Pharmacology and Therapeutics, School of Medicine, National University of Ireland, Galway, Ireland 2Metabolic Research Laboratories, Wellcome Trust-MRC Institute of Metabolic Science-Metabolic Research Laboratories, University of Cambridge and National Institute for Health Research Cambridge Biomedical Research Centre, Addenbrooke's Hospital, Cambridge, UK

${ }^{3}$ Department of Clinical Biochemistry, Galway University Hospitals, Saolta Hospitals Group, Galway, Ireland

${ }^{4}$ Department of Endocrinology, Diabetes, and Clinical Nutrition, University Hospital Zurich, Zurich, Switzerland

${ }^{5}$ Medizinische Klinik und Poliklinik III, University Hospital Carl Gustav Carus Dresden, Dresden, Germany

Correspondence should be addressed to M C Dennedy: michael.dennedy@nuigalway.ie

\begin{abstract}
Adrenocortical carcinoma (ACC) is a rare aggressive malignancy with a poor outcome largely due to limited treatment options. Here, we propose a novel therapeutic approach through modulating intracellular free cholesterol via the liver $\mathrm{X}$ receptor alpha (LXR $\alpha)$ in combination with current first-line pharmacotherapy, mitotane. H295R and MUC-1 ACC cell lines were pretreated with LXR $\alpha$ inhibitors in combination with mitotane. In H295R, mitotane $(20,40$ and $50 \mu \mathrm{M})$ induced dose-dependent cell death; however, in MUC-1, this only occurred at a supratherapeutic concentration $(200 \mu \mathrm{M})$. LXR $\alpha$ inhibition potentiated mitotane-induced cytotoxicity in both cell lines. This was confirmed through use of the CompuSyn model which showed moderate pharmacological synergism and was indicative of apoptotic cell death via an increase in annexinV and cleaved-caspase 3 expression. Inhibition of LXR $\alpha$ was confirmed through downregulation of cholesterol efflux pumps $A B C A 1$ and $A B C G 1$; however, combination treatment with mitotane attenuated this effect. Intracellular free-cholesterol levels were associated with increased cytotoxicity in H295R $\left(r^{2}=0.5210\right)$ and MUC-1 $\left(r^{2}=0.9299\right)$ cells. While both cell lines exhibited similar levels of free cholesterol at baseline, H295R were cholesterol ester rich, whereas MUC-1 were cholesterol ester poor. We highlight the importance of LXR $\alpha$ mediated cholesterol metabolism in the management of ACC, drawing attention to its role in the therapeutics of mitotane sensitive tumours. We also demonstrate significant differences in cholesterol storage between mitotane sensitive and resistant disease.
\end{abstract}

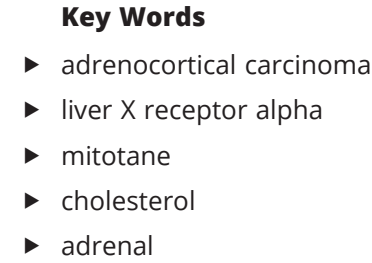

Endocrine-Related Cancer (2020) 27, 361-373

\section{Introduction}

Adrenocortical carcinoma (ACC) is a rare, aggressive malignancy with an incidence of 2-5 per million and which carries a poor prognosis due to local invasion or distant metastases at the time of diagnosis in the majority of cases (Fassnacht et al. 2013, Libe 2019). Complete surgical resection (R0) is the only curative therapy (de Reynies et al. 2009, Kerkhofs et al. 2013). Yet, for those on whom R0 resection is achieved, disease recurs in 50-85\% (Pommier \& Brennan 1992, Terzolo et al. 2007). Mitotane is the only currently licensed pharmacotherapy for adjuvant use or for recurrent disease and remains the most effective drug (alone or in combination with
(C) 2020 The authors Published by Bioscientifica Ltd. Printed in Great Britain

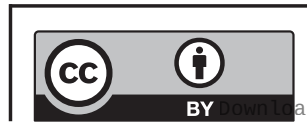

This work is licensed under a Creative Commons Attribution 4.0 International License. 
platinum based chemotherapy regimens) in preventing and treating recurrence (Haak et al. 1994, Terzolo et al. 2007, 2013, Fassnacht et al. 2018). Mitotane's use is limited by its narrow therapeutic window, whereby at serum concentrations below $14 \mathrm{mg} / \mathrm{L}$, it demonstrates poor efficacy, while at concentrations $>20 \mathrm{mg} / \mathrm{L}$, it is associated with unacceptable toxic effects (Hermsen et al. 2011, Terzolo et al. 2013). There is significant clinical need to improve the therapeutic options in managing persistent or recurrent ACC, and in this context, the current study investigates therapeutic strategies to enhance the efficacy and tolerability of mitotane.

Mitotane has been used for 50 years in the management of adrenocortical neoplasm (Montgomery \& Welbourn 1965), yet its adrenotoxic mechanism remains incompletely understood (Hescot et al. 2013, Lehmann et al. 2013, Poli et al. 2013). Sbiera et al. demonstrated that mitotane-induced adrenotoxicity is associated with intracellular free-cholesterol (FC) accumulation causing endoplasmic reticulum (ER) stress (Sbiera et al. 2015). The authors also demonstrated that mitotane-induced FC accumulation is associated with inhibition of sterolO-acyltransferase-1 (SOAT1) which usually converts FC to inert cholesteryl esters (CE) for intracellular storage. The adrenal-cytotoxic effects of SOAT1 inhibition have also been demonstrated by LaPensee et al. through the use of the selective inhibitor ATR-101 (LaPensee et al. 2016). Consequently, this lipotoxic mechanism mediated by intracellular FC accumulation is considered significant or even predominant in terms of mitotane-induced adrenotoxicity.

We theorised that the lipotoxic effects of mitotane on ACC cells could be enhanced by targeting complementary mechanisms to that of SOAT1 inhibition, which would further increase intracellular FC. Liver X receptor alpha (LXR $\alpha / \mathrm{NR} 1 \mathrm{H} 3$ ) inhibition represents one such mechanism. LXR $\alpha$ is a nuclear receptor, sensitive to intracellular FC and represents the predominant transcriptional mechanism mediating reverse cholesterol transportation to the liver (Costet et al. 2000, Kennedy et al. 2005, Wang et al. 2007). At rest, LXR $\alpha$ is bound to its nuclear response element and held in an inactive state by co-repressor molecules. Upon ligand activation, it recruits co-activator proteins to dimerise with the retinoid X receptor (RXR), and in turn transcribes regulatory proteins for cholesterol efflux, namely ABCA1 and ABCG1. These deliver excessive intracellular FC to circulating apolipoprotein (Apo) A1 or high density lipoprotein $\left(\mathrm{HDL}_{1}\right)$ (Janowski et al. 1996, Fu et al. 2001, Hu et al. 2003, Huuskonen et al. 2004, Phelan et al. 2008).
LXR $\alpha$ is highly expressed in liver, innate immune cells and adrenal cortex (Cummins et al. 2006) and its sensitivity to intracellular cholesterol is effected through endogenous ligand molecules, oxysterols, generated from precursor cholesterol. The common oxysterol, 27-hydroxycholesterol (27HC, also known as (25R)26-HC), is catalysed by CYP27A1 and highly expressed in the adrenal cortex (Chen et al. 1998, Fedorova et al. 2015). Higher intracellular FC results in increased oxysterol production, activating LXR $\alpha$ dependent transcription of cholesterol efflux pumps. The cholesterol regulatory function of LXR $\alpha$ is conserved across cell types, mediating reverse cholesterol transport as well as providing cellular protection against toxic FC accumulation (Cignarella et al. 2005, Engel et al. 2007).

In the adrenal, oxysterols and LXR $\alpha$ also have a tissue-specific role, whereby they increase steroidogenesis by upregulating steroidogenic acute regulatory (StAR) protein (Cummins et al. 2006, Nilsson et al. 2007). In breast and prostate cancer, LXR $\alpha$ stimulation facilitates cancer cell survival which is partially explained by its role to enhance aerobic glycolysis, while also hypothesised to reduce FC-induced cytotoxicity (Nelson et al. 2013, Flaveny et al. 2015, Kim et al. 2018).

We hypothesised that inhibition of LXR $\alpha$-modulated cholesterol efflux pump expression could potentiate mitotane-induced lipotoxic adrenocortical cell death at usually subtherapeutic mitotane concentrations. We investigated the dose-dependent interactions of mitotane with pharmacological inhibition of LXR $\alpha$ and dominantnegative (DN) interference of LXR $\alpha$ activity in two human ACC cell lines (H295R and MUC-1). Using this strategy, we demonstrate an enhanced ability of mitotane in combination with LXR $\alpha$ inhibition to kill ACC cells at lower concentrations than for mitotane alone. We show that this effect is associated with higher intracellular FC accumulation.

\section{Materials and methods}

\section{Cell culture and treatments}

H295R human primary ACC cells (NCI-H295R, CRL-2182; (American Type Culture Collection)) (Rainey et al. 1994) were maintained in DMEM/F12 (Thermo Fisher), containing $2.5 \% \mathrm{Nu}$ serum (Corning), 1\% ITS+ (Corning), 1\% penicillin/streptomycin. H295R cells were isolated from a primary adrenocortical tumour of a 48-year-old black female and are mitotane sensitive.

This work is licensed under a Creative Commons Attribution 4.0 International License. 
MUC-1 human metastatic ACC cells were established by Hantel et al. (2016) and maintained in DMEM Advanced (Thermo Fisher) containing 5\% fetal bovine serum (FBS) and 1\% penicillin/streptomycin. Originally isolated from a neck metastasis of a 24-year-old male, MUC-1 cells are an aggressive, mitotane resistant model of ACC. HepG2 human hepatocellular carcinoma cells (HB-8065 ${ }^{\mathrm{TM}}$; (American Type Culture Collection)) were utilised as a comparator cell line and maintained in Eagle's MEM (Thermo Fisher), containing 5\% FBS, 1\% penicillin/streptomycin (Di et al. 2012, Bruschi et al. 2019). Cells were grown in a humidified atmosphere containing $5 \% \mathrm{CO}_{2}$ and $37^{\circ} \mathrm{C}$, used between passage 3-10 (H295R/HepG2) or passage 21-26 (MUC-1). H295Rs were obtained from ATCC (July 2017) and cells are routinely tested for steroid production, forskolin responsiveness and cell line characteristics.

\section{Pharmacological treatments}

Cells were treated at the indicated concentrations of GSK2033-LXR $\alpha$ antagonist (Bio-techne, Minneapolis, MN, USA) (Griffett \& Burris 2016), SR9243-LXR $\alpha$ inverse agonist (Flaveny et al. 2015), 27-hydroxycholesterol-endogenous LXR $\alpha$ agonist (Enzo Life Sciences), T0901317-synthetic, non-steroidal LXR $\alpha$ agonist and mitotane (2,4'-DDD). Cells were cholesterol loaded by preparing supplemented media using $45 \mu \mathrm{g} / \mathrm{mL}$ water-soluble cholesterol methyl$\beta$-cylodextrin. All drugs were prepared in DMSO and the vehicle control remained below 0.1\% at all times. H295R cells were pretreated with GSK2033 $(5 \mu \mathrm{M})$, SR9243 $(1 \mu \mathrm{M})$ or $27 \mathrm{HC}(5 \mu \mathrm{M})$ for $18 \mathrm{~h}$ followed by mitotane $(20,40$, $50 \mu \mathrm{M})$ for $6 \mathrm{~h}$. MUC-1 cells were pretreated with SR9243 (5 $\mu \mathrm{M})$ for $24 \mathrm{~h}$ followed by mitotane (50, 100 and $200 \mu \mathrm{M})$ for $24 \mathrm{~h}$. Both cell lines were cholesterol loaded $1 \mathrm{~h}$ prior to mitotane treatment. Reagents were obtained from Sigma unless otherwise indicated.

\section{Plasmids, transfection and luciferase assay}

H295R were transfected using Lipofectamine 3000 (Thermo Fisher) using either pCMX-hLXR $\alpha$ dominant-negative (LXR-DN) or WT (LXR-WT) expressing plasmids(Willy et al. 1995). Transfection efficiency was evaluated using green fluorescent protein co-expression (pmaxGFP, Lonza) using microscopy and flow cytometry (Supplementary Fig. 1I and $\mathrm{J}$, see section on supplementary materials given at the end of this article). H295R were transfected in antibiotic free media for $24 \mathrm{~h}$ prior to drug treatments. Luciferase assay was carried out using firefly (pGL3-TK-LXRRE-Luc) and renilla luciferase vectors (10:1). Activity were measured following 24-h stimulation with LXR $\alpha$ agonist T0901317 (1 $\mu \mathrm{M})$ using the Dual-Glo Luciferase Assay System (Promega) according to the manufacturer's guidelines. Luminescence was recorded on the Synergy HT Multi-Detection Microplate Reader (BioTek), normalised for renilla luciferase activity and represented as relative light units (RLU).

\section{Gene expression}

Following drug treatments, cells were washed with cold phosphate buffered saline (PBS) and total RNA was extracted from adherent cells using TRI Reagent ${ }^{\circledR}$. Following spectrophotometric quantification, $1 \mu \mathrm{g}$ of total RNA was reverse transcribed into cDNA using the Qiagen $\mathrm{RT}^{2}$ first strand kit. PCR assay was carried out using Go Taq ${ }^{\circledR}$ Green Master Mix (Promega), according to manufacturer's guidelines. Amplified products were separated using a 4\% agarose gel, visualized using SYBR Safe (Thermo Fisher) stain and imaged using the ChemiDoc ${ }^{\mathrm{TM}} \mathrm{XRS}+$ Imaging system (Bio-Rad Laboratories). Real-time quantitative PCR expression was assayed on Applied Biosystems StepOne Plus (Applied Biosystems) and carried out using SYBR green mastermix (Promega). Primer sequences are listed in Supplementary Table 1. Fold change was calculated using the $\Delta \Delta \mathrm{CT}$ method. Data is represented as fold change of mRNA relative to vehicle control.

\section{Western blotting}

Samples were harvested on ice and lysed using radioimmuno-precipitation (RIPA) buffer and $1 \mathrm{X}$ protease inhibitor cocktail (Calbiochem). Lysates were quantified by BCA assay, denatured at $95^{\circ} \mathrm{C}$ and separated by SDS-PAGE using a $10 \%$ Tris-glycine gel. Proteins were transferred to PVDF membrane, blocked using 5\% milk and incubated with relevant antibodies. Membranes were incubated with primary antibodies overnight at $4^{\circ} \mathrm{C}$ followed by relevant HRP-linked secondary antibodies (Supplementary Table 2). Imaging was carried out using the ChemiDoc ${ }^{\mathrm{TM}} \mathrm{XRS}+$ Imaging system (Bio-Rad Laboratories) with SuperSignal ${ }^{\mathrm{TM}}$ HRP substrate (Thermo Fisher) and Image Lab ${ }^{\text {TM }}$ Software (Bio-rad, V5.2.1). Semi-quantitative densitometry was carried out using ImageJ and normalised to the loading control ( $\beta$ Actin).

\section{Cell death and apoptosis}

H295R were grown as described and stained with Calcein AM (Invitrogen) $(1 \mu \mathrm{M})$ and propidium iodide

This work is licensed under a Creative Commons Attribution 4.0 International License. 
(PI) $(5 \mu \mathrm{g} / \mathrm{mL})$ to assess viability via microscopy, all images $(10 \times)$ were taken using the EVOS® Cell Imaging System (Thermo Scientific). For quantitative analysis, cells were trypsinised and resuspended in FACS buffer (PBS, 1\% FBS, 0.05\% sodium azide) following treatment. AnnexinV:FITC (Bio-Rad) staining was carried out at $10 \mu \mathrm{L} / 10^{6}$ cells for $30 \mathrm{~min}$, followed by 5 -min PI staining. All fluorochromes were excited using a $488 \mathrm{~nm}$ laser followed by 530/30 (AnnexinV:FITC) and 585/35 (PI) bandpass filter. Compensated flow cytometry was performed on FACS CantoII ${ }^{\circledR}$ with FACS DiVa 6.0® acquisition software (BD Biosciences) and FlowJo ${ }^{\circledR}$ V10 analysis software (Tree Star Inc., Ashland, OR, USA). Gating strategy is described in Supplementary Fig. 2. AnnexinV and PI positive cells are represented as \% cells relative to vehicle control.

\section{Metabolic activity assay}

MTT assay was carried out in 96 well plates, cells were seeded at $1 \times 10^{3}$ cells per well and grown for 3, 7, 10 and 14 days. Drug treatments GSK2033 $(5 \mu \mathrm{M})$ and SR9243 $(1 \mu \mathrm{M})$ were given at the indicated time points (day 0 , $3,7$ and 10$)$ for $24 \mathrm{~h}$ followed by mitotane $(50 \mu \mathrm{M})$ for $24 \mathrm{~h}$. Following incubation, MTT reagent $(0.5 \mathrm{mg} / \mathrm{mL})$ was added. The assay was terminated by solubilising MTT using DMSO and absorbance was read at $570 \mathrm{~nm}$ as described previously. Experimental conditions were carried out in replicates of six and the experiment was repeated four times. Data is represented as \% metabolic activity adjusted to matched vehicle control (100\%) for each individual time point.

\section{Cholesterol analysis}

Filipin complex III (Sigma) from Streptomyces filipinensis was used to assess free cholesterol (Hassall \& Graham 1995). Filipin is a fluorescent marker of FC that is excited by a 405-nm laser followed by a 450/50 bandpass filter. Cells were treated as indicated, harvested via trypsinisation and fixed using fixation buffer (BioLegend, San Diego, CA, USA) according to manufacturer's guidelines. Staining was carried out at $1 \mathrm{mg} / \mathrm{mL}$ for $1 \mathrm{~h}$ at $4^{\circ} \mathrm{C}$ in darkness and analysed by microscopy and flow cytometry. CholEsteryl BODIPYTM FL C12 (cholesteryl 4,4-difluoro-5,7dimethyl-4-bora-3a,4a-diaza-s-indacene-3-dodecanoate) (Invitrogen) was used to label cholesterol esters (Hsieh et al. 2012). Cells were grown to $60 \%$ confluence and media was supplemented with $5 \mu \mathrm{M}$ CholEsteryl BODIPYTM FL C12 overnight. Cells were harvested via trypsinisation and analysed by flow cytometry on the BD FACSCantoII
(BD Bioscience). Sytox blue (Invitrogen) $(1 \mu \mathrm{M})$ was used as a viability dye. Fluorescence was recorded using a $488-\mathrm{nm}$ excitation laser followed by a $530 / 30$ bandpass filter (CholEsteryl BODIPYTM FL C12) and a 405-nm laser followed by $450 / 50$ bandpass filter (Sytox Blue). Single, live cells were gated according to Supplementary Fig. 6 and the resolution metric was calculated as described (Brando \& Sommaruga 1993). Additionally, cells were analysed via imaging flow cytometry using the Amnis® ImageStream ${ }^{\circledR} \times \mathrm{Mk}$ II (Luminex Corporation, Seattle, WA, USA). High sensitivity mode (60x) was used to record 3500 events per sample. Analysis was carried out using IDEAS $®$ software (V6.2) and, briefly, focused cells were gated according to Gradient RMS_M01_Ch01 $(<50)$. Single cells were gated using Area_M01 vs Aspect Ratio_M01 (size vs circularity). Live cells were gated by using Sytox Blue (Invitrogen) viability dye according to Intensity_MC_ Ch07. The population of live, single, focused cells was used for analysis of CholEsteryl BODIPYTM FL C12 according to Intensity_MC_Ch02. Image display properties were standardised as follows: X Range $(37,563)$, Midpoint $(300,127)$ and $\mathrm{X}$-Axis Scale $(32,568)$.

\section{Data analysis}

Drug synergism was evaluated using CompuSyn (download from www.compusyn.com) according to the Chou-Talalay method (Chou 2008). Data were input as single agent and combined (non-constant ratio) agents as mean \pm s.E.M. Pharmacological synergism was interpreted according to the combination index (CI) model. CI plots and data tables are available in Supplementary Fig. $1 \mathrm{~K}, \mathrm{~L}$ and $\mathrm{M}$. Linear regression and statistical analyses were performed using GraphPad® Prism V 8.0 (GraphPad Software). Data is represented as mean \pm s.E.M. unless stated otherwise. Paired sample analyses were performed using a two-sided Student's $t$-test. Multiple-group comparisons were carried out using an ANOVA followed by Tukey's post-hoc test. Statistical significance for two-tailed analyses ( $P$-value) was assigned for values $<0.05$.

\section{Results}

LXR $\alpha$ inhibition combined with mitotane enhances ACC cell death and significantly reduces ACC cell metabolic activity, when compared to mitotane alone

Mitotane produced dose-dependent cytotoxicity in H295R in line with previous findings $(15,27$ and 28) (Fig. 1A

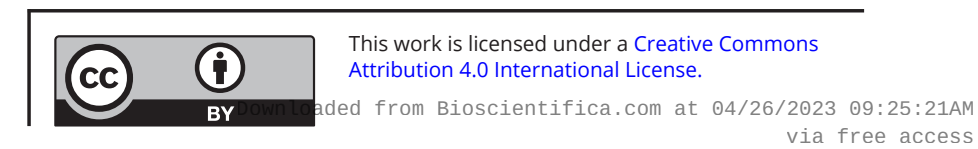


and Supplementary Fig. 1A) with maximally observed adrenocortical cell death occurring at the therapeutic concentration of $50 \mu \mathrm{M}(16 \mathrm{mg} / \mathrm{L})$ (Fig. 1A). For the mitotane-resistant ACC cell line MUC-1, significant cell death was observed only at the supratherapeutic concentration of $200 \mu \mathrm{M}$ mitotane $(64 \mathrm{mg} / \mathrm{L}$ ) (Fig. 1C and Supplementary Fig. 1D). Consistent with previous findings, cell death in MUC-1 (49.1\%, mitotane $200 \mu \mathrm{M})$ was significantly lower than that observed for H295R (66.2\%, mitotane $50 \mu \mathrm{M})$ (Hantel et al. 2016).

Co-treatment of H295R with LXR $\alpha$ inhibitors (GSK2033 $(5 \mu \mathrm{M})$ or SR9243 $(1 \mu \mathrm{M}))$ and mitotane significantly increased cell death at subtherapeutic mitotane concentration of $20 \mu \mathrm{M} \quad(16 \%$ (mitotane) vs $\quad 39 \% \quad$ (GSK2033 + mitotane), $\quad P<0.0001 ; \quad 27 \%$ (SR9243+mitotane), $P=0.0308)$. This effect was also present for co-treatment of either agent with $40 \mu \mathrm{M}$ mitotane (32\% (mitotane) vs 52\% (GSK2033 + mitotane), $P<0.0001$; vs 47\% (SR9243 + mitotane) $P=0.0006$ ) and with $50 \mu \mathrm{M}$ mitotane co-treated with SR9243 (66\% (mitotane), 76\% (SR9243+mitotane); $P=0.0194$ ) (Fig. $1 \mathrm{~A}$ and B).
For MUC-1, LXR $\alpha$ inhibition with SR9243 only increased ACC cell death at mitotane $200 \mu \mathrm{M}$ (46\% (mitotane) vs $69 \%$ (SR9243 + mitotane), $P<0.0001$ ) (Fig. 1C).

A time-course experiment demonstrated significantly reduced cell metabolic activity of H295R and MUC-1 in the presence of $50 \mu \mathrm{M}$ mitotane alone or in combination with LXR $\alpha$ inhibitors (Fig. 1D, E and Supplementary Table 3). This effect was greater in H295R and reached significance at day 3 in H295R (18\% (mitotane), $P<0.0001 ; 15 \%$ (GSK2033 + mitotane), $P<0.0001 ; 9 \%$ (SR9243+mitotane) $P<0.0001)$ and at day 7 in MUC-1 (72\% (mitotane), $P<0.0001 ; \quad 58 \% \quad$ (GSK2033 + mitotane) $\quad P<0.0016$; $60 \%$ (SR9243 + mitotane), $P<0.0089$ ).

We validated these findings of pharmacological LXR $\alpha$ inhibition by transfecting H295R cells with a LXR $\alpha$ dominant-negative construct (LXR $\alpha-\mathrm{DN}$, transfection efficiency: 40\%) that blocks LXR $\alpha$-WT functioning (Supplementary Fig. 1G, H, I and J). LXR $\alpha$-DN-expressing cells reached significantly higher rates of mitotaneinduced cytotoxicity for all mitotane concentrations, compared to LXR $\alpha$-WT (11\% (WT:mitotane $20 \mu \mathrm{M})$ vs
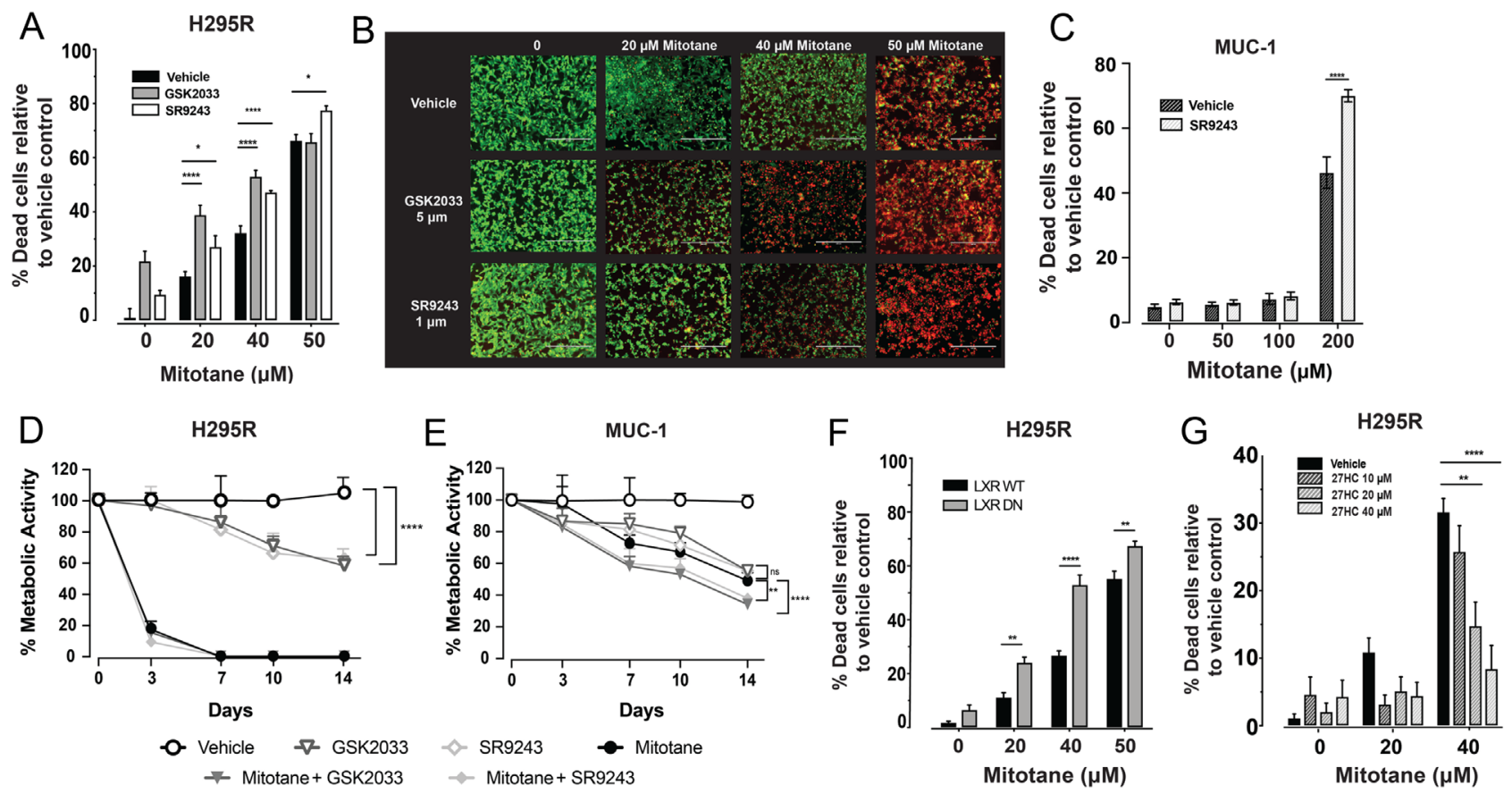

\section{Figure 1}

(A) Graphical representation of percentage cell death using pharmacological inhibitors of LXR $\alpha$, GSK2033 (5 $\mu$ M) and SR9243 (1 $\mu$ M) to potentiate mitotane killing in H295R as quantified by flow cytometric analysis and (B) microscopy. (C) Graphical representation of percentage cell death using SR9243 (5 $\mu$ M) to potentiate mitotane killing in MUC-1 as quantified by flow cytometric analysis. Graphical representation of percentage metabolic activity of (D) H295R and (E) MUC-1 following GSK2033 (5 $\mu \mathrm{M})$ and SR9243 $(5 \mu \mathrm{M})$ alone and in combination with $50 \mu \mathrm{M}$ mitotane at day 3, 7, 10 and 14, as quantified by MTT assay and adjusted to matched vehicle control. (F) Graphical representation of percentage cell death following transfection with LXR $\alpha$ dominant negative (LXR-DN) vs LXR $\alpha$ WT (LXR-WT) in combination with mitotane in H295R cells. (G) Graphical representation of percentage dead cells following 27HC treatment in combination with mitotane in H295R. Viability data represented as percentage dead cells relative to vehicle control. Metabolic activity data represented as percentage cells relative to vehicle control (adjusted to $100 \%$ at each respective time point). All data shown as mean \pm S.E.M., $n=4$. Statistical significance is denoted as $* P<0.05, * \star P<0.01, * \star \star P<0.01$ and $* \star \star * P<0.001$ relative to vehicle control or as otherwise indicated.

https://erc.bioscientifica.com https://doi.org/10.1530/ERC-20-0031 (c) 2020 The authors Published by Bioscientifica Ltd. Printed in Great Britain
This work is licensed under a Creative Commons Attribution 4.0 International License. ed from Bioscientifica.com at 04/26/2023 09:25:21AM 
24\% (DN:mitotane $20 \mu \mathrm{M}$ ), $P=0.0044 ; 27 \%$ (WT:mitotane $40 \mu \mathrm{M})$ vs 53\% (DN:mitotane $40 \mu \mathrm{M}$ ), $P<0.001 ; 55 \%$ (WT:mitotane $50 \mu \mathrm{M}$ ) vs $67 \%$ (DN:mitotane $50 \mu \mathrm{M}$ ), $P=0.0089)$ ) (Fig. 1F). These findings suggest an LXR $\alpha-$ mediated mechanism of enhanced mitotane-induced cytotoxicity. We validated these results by stimulating $\mathrm{LXR} \alpha$ activity using the endogenous ligand oxysterol 27HC. 27HC reduced mitotane-induced cytotoxicity in $\mathrm{H} 295 \mathrm{R}$ at concentrations between 10 and $40 \mu \mathrm{M}$ (32\% (mitotane) vs $27 \%$ (mitotane+27HC $10 \mu \mathrm{M}$ ), $P=0.265$; vs $15 \%$ (mitotane $+27 \mathrm{HC} 20 \mu \mathrm{M}$ ), $P=0.0002$; vs $8 \%$ (mitotane $+27 \mathrm{HC} 40 \mu \mathrm{M}), P<0.0001$ ) (Fig. 1G).

Pharmacological inhibition of LXR $\alpha$ alone with GSK2033 or SR9243 reduced cell metabolic activity in both cell lines and this effect was similar across all timepoints (Fig. 1D and E). LXR $\alpha$ inhibition using GSK2033 but not SR9243 had a moderately induced dose-dependent cell death in H295R but not MUC-1 (Supplementary Fig. 1B, $\mathrm{C}, \mathrm{E}$ and F). We calculated the combination index (CI) using CompuSyn to investigate cytotoxic mechanistic synergy between mitotane and LXR $\alpha$ inhibition. SR9243 demonstrated CI values $<1.0$, indicative of modest synergy with mitotane for its cytotoxic effects in H295R across all doses (0.7 (SR9243+mitotane $20 \mu \mathrm{M}) ; 0.95$ (SR9243+mitotane $40 \mu \mathrm{M}$ ); $0.64 \quad$ (SR9243+mitotane $50 \mu \mathrm{M}) ; \quad 0.59 \quad$ (GSK2033 + mitotane $20 \mu \mathrm{M}) ; \quad 0.86$ (GSK2033+mitotane $40 \mu \mathrm{M}) ; 0.84$ (GSK2033+mitotane $50 \mu \mathrm{M})$ ) and for MUC-1 at mitotane $200 \mu \mathrm{M}$ only
(0.81 (SR9243 + mitotane $200 \mu \mathrm{M})$ ) (Supplementary Fig. $1 \mathrm{~K}, \mathrm{~L}$ and $\mathrm{M})$.

The early apoptosis marker AnnexinV increased dosedependent for all mitotane concentrations in the presence and absence of GSK2033 or SR9243 in H295R (Fig. 2A). The combination of mitotane with GSK2033 resulted in higher AnnexinV expression vs $40 \mu \mathrm{M}$ mitotane alone (32\% (mitotane $40 \mu \mathrm{M}$ ) vs 50\% (GSK2033+mitotane 40 $\mu \mathrm{M}), P=0.0004)$. Combination with SR9243 demonstrated higher AnnexinV expression vs all mitotane alone (10\% (mitotane $20 \mu \mathrm{M})$ vs $26 \%$ (SR9243+mitotane $20 \mu \mathrm{M}), \quad P=0.0008 ; 32 \%$ (mitotane $40 \mu \mathrm{M}$ ) vs $53 \%$ (SR9243 + mitotane $40 \mu \mathrm{M}$ ),$P<0.0001 ; 52 \%$ (mitotane 50 $\mu \mathrm{M})$ vs $67 \%$ (SR9243+mitotane $50 \mu \mathrm{M}), P=0.0008)$. The late apoptosis marker, cleaved caspase 3 , was also increased for mitotane at doses of $40 \mu \mathrm{M}$ and $50 \mu \mathrm{M}$, reflective of the higher cell death at these mitotane concentrations. Higher cleaved-caspase 3 expression was present for the combination with either LXR $\alpha$ inhibitor vs $40 \mu \mathrm{M}$ or 50 $\mu \mathrm{M}$ mitotane alone (Fig. 2B and Supplementary Fig. 3A, B). There was also higher expression of the ER stress markers $C H O P$ and $X B P 1_{S / U}$ in mitotane-treated H295R across all concentrations, which increased in combination with either LXR $\alpha$ inhibitor (Fig. 2C).

For MUC-1, higher cell death at $200 \mu \mathrm{M}$ mitotane was also reflected in higher expression of AnnexinV, which in turn was significantly higher with LXR $\alpha$ inhibition with SR9234 (3\% (VehicleControl) vs 22.6\% (mitotane $50 \mu \mathrm{M}$ ),

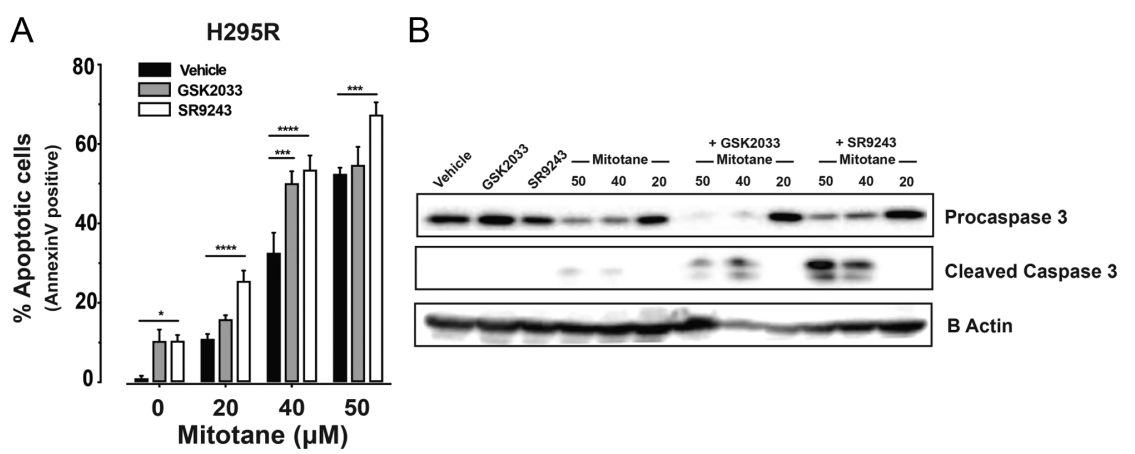

C
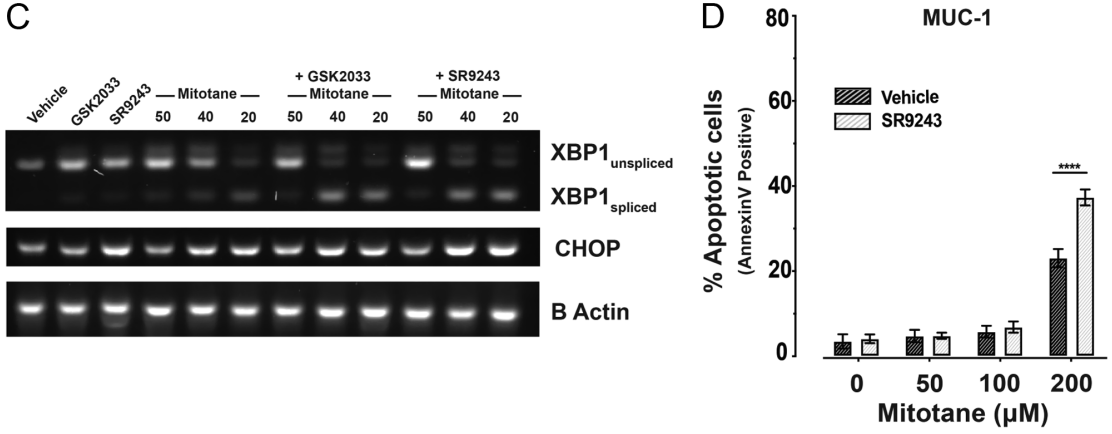

Figure 2

(A) Graphical representation of percentage AnnexinV positive cells showing an increase in apoptosis following GSK2033 (5 $\mu$ M) or SR9243 (1 $\mu \mathrm{M})$ alone and in combination with mitotane treatment in H295R as quantified by flow cytometric analysis. (B) Western blotting image represents procaspase-3, cleaved caspase- 3 and $\beta$ actin expression following GSK2033 $(5 \mu \mathrm{M})$ or SR9243 $(1 \mu \mathrm{M})$ alone and in combination with mitotane treatment in H295R. (C) Electrophoresis gel image representing XPB1 $1_{\text {unspliced }}$ XBP1 $1_{\text {spliced }}$ CHOP and $\beta$ actin mRNA expression following GSK2033 $(5 \mu \mathrm{M})$ or SR9243 $(1 \mu \mathrm{M})$ alone and in combination with mitotane treatment in H295R. (D) Graphical representation of percentage Annexin $V$ positive cells showing an increase in apoptosis in SR9243 $(5 \mu \mathrm{M})$ vs mitotane alone in MUC-1 as quantified by flow cytometric analysis. Western blot image is representative of three independent experiments. Data are represented as mean \pm S.E.M. $(n=4)$, statistical comparisons were performed using two-way ANOVA followed by Tukey's post-hoc analysis. Statistical significance is denoted as $* P<0.05, * \star P<0.01$, $\star * \star P<0.01$ and $* \star \star * * P<0.001$ relative to vehicle control or as otherwise indicated. https://erc.bioscientifica.com https://doi.org/10.1530/ERC-20-0031 (c) 2020 The authors Published by Bioscientifica Ltd. Printed in Great Britain
This work is licensed under a Creative Commons Attribution 4.0 International License. 
$P<0.0001 ; 22.6 \%$ (mitotane $50 \mu \mathrm{M}$ ) vs 39\% (SR9243 mitotane $50 \mu \mathrm{M}), P<0.0001)$ ) (Fig. 2D).

\section{$\mathrm{LXR} \alpha$ inhibition reduces expression of cholesterol efflux pumps in H295R and MUC-1 ACC cells}

In H295R and MUC-1, LXR $\alpha$ expression at baseline (Fig. $3 \mathrm{~A}$ and $\mathrm{B}$ ) was equivalent to expression in the positive control HepG2 hepatocellular carcinoma cells. Similarly, high expression levels of the oxysterol synthetic enzyme CYP27A1 were detected (Fig. 3A and B). Transfection with a luciferase construct under the control of an
LXR $\alpha$-responsive element (TK-LXRRE-Luc) showed significant constitutive baseline activation of $\mathrm{LXR} \alpha$, which was increased by stimulation with the LXR $\alpha$ agonist T0901317 (1 $\mu \mathrm{M})$ (Fig. 3C). These data indicate high activity of the LXR $\alpha /$ oxysterol pathway in adrenal cells, equivalent to that of hepatic tissue.

Expression of LXR $\alpha$ target genes, the FC efflux pumps, $A B C A 1$ and $A B C G 1$, were reduced by each $L X R \alpha$ inhibitor in H295R and MUC-1, respectively (Fig. 3D, E, F, G and Supplementary Fig. 4A, B, C, D). In line with these findings, expression of $A B C A 1$ and $A B C G 1$ increased in both cell lines when stimulated using the non-steroidal
A

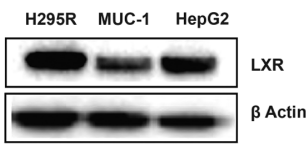

B

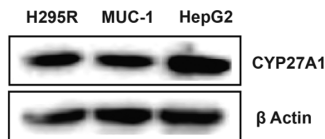

$\mathrm{D}$

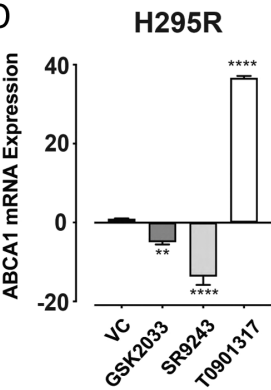

$\mathrm{H}$

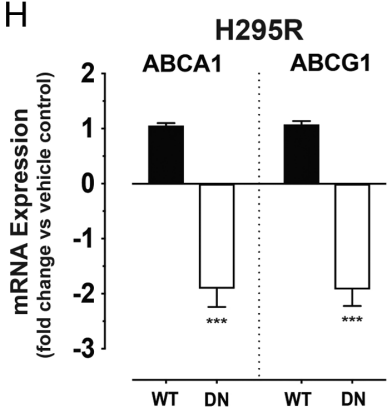

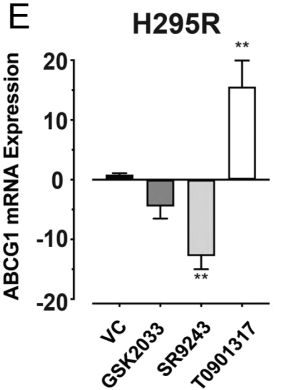

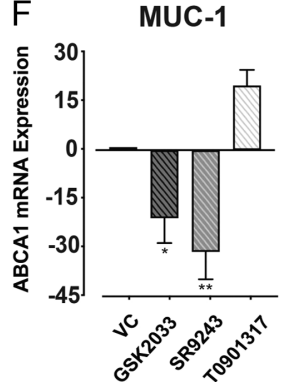

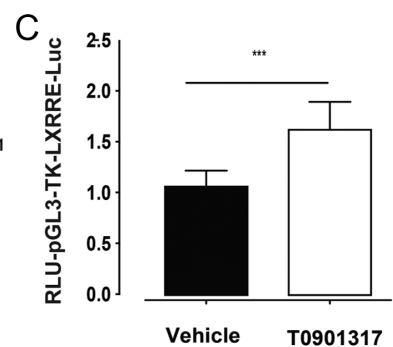

Vehicle T0901317
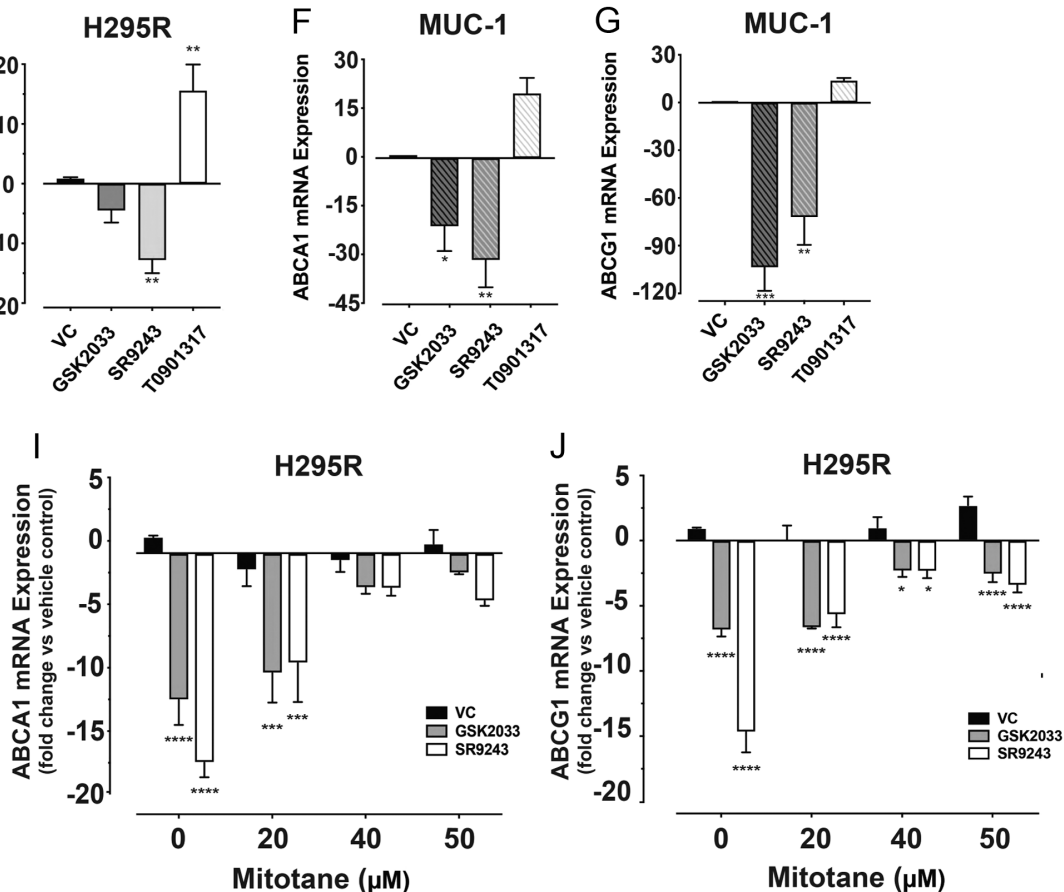

\section{Figure 3}

(A) Western blot images demonstrating protein expression of LXR $\alpha$ and (B) CYP27A1 in H295R, MUC-1 and HepG2 cell lines relative to $\beta$ actin. (C) Graphical representation of luciferase activity in relative luciferase units (firefly/renilla) at baseline and following LXR $\alpha$ agonist T0901317 (1 $\mu$ M) stimulation in transient transfected H295R cells with TK-LXRRE-Luc as reporter assay and a renilla luciferase control plasmid. (D) Graphical representation of $A B C A 1$ and (E) ABCG1 mRNA expression as fold change relative to vehicle control following GSK2033, SR9243 and T0901317 stimulation in H295R and (F and G) MUC-1. (H) Graphical representation of $A B C A 1$ and $A B C G 1$ mRNA expression as fold change relative to WT transfected vs $L X R \alpha$ dominant-negative (DN) transfected H295R. (I) Graphical representation of $A B C A 1$ and (J) ABCG1 mRNA expression as fold change relative to vehicle control (VC) following GSK2033 $(5 \mu \mathrm{M})$ and SR9234 $(1 \mu \mathrm{M})$ treatment alone and in combination with mitotane in H295R. Western blot image is representative of three independent experiments. Data are represented as mean \pm S.E.M. $(n=4)$, statistical comparisons were performed using a two-tailed $t$-test or a two-way ANOVA followed by Tukey's post-hoc analysis. Statistical significance is denoted as $* P<0.05, * * P<0.01, * * * P<0.01$ and $* * \star \star P<0.001$ relative to vehicle control or as otherwise indicated.

https://erc.bioscientifica.com https://doi.org/10.1530/ERC-20-0031
(C) 2020 The authors Published by Bioscientifica Ltd. Printed in Great Britain
This work is licensed under a Creative Commons Attribution 4.0 International License. 
LXR $\alpha$ agonist T0901317 (Fig. 3D, E, F and G). Expression for $A B C A 1$ and $A B C G 1$ also decreased in the presence of the LXR $\alpha$-DN construct (Fig. 3H), confirming direct involvement of LXR $\alpha$ in their expression.

The responses of $A B C A 1$ and $A B C G 1$ in the presence of increasing concentrations of mitotane did not significantly change (Fig. 3I and J). However, the efficacy of GSK2033 or SR9243 to reduce ABCA1 and ABCG1 expression were attenuated with mitotane treatment in a dose-dependent manner, which is unlikely to reflect a direct effect of mitotane on cholesterol efflux pumps. However, this may be explained by increasing intracellular FC accumulation at higher mitotane doses. We next investigated intracellular cholesterol within this model.

\section{LXR $\alpha$ inhibition enhances mitotane-induced toxic accumulation of free cholesterol in H295R ACC cells}

Mitotane exposure resulted in a dose-dependent increase in intracellular FC in H295R, reaching significance at all mitotane concentrations (Fig. 4A) $(15,16)$. The inhibition of LXR $\alpha$ with GSK2033 and SR9243 significantly increased intracellular FC in H295R at baseline and in combination with mitotane, with higher levels for each dose of mitotane vs mitotane alone (Fig. 4A and Supplementary Fig. 5A). For MUC-1, only the cytotoxic $200-\mu \mathrm{M}$ mitotane concentration resulted in a significant increase in intracellular FC, increased further with SR9243 (Fig. 4B). Cell death and intracellular cholesterol correlated for both cell lines: H295R $\left(r^{2}=0.5210, P=0.008\right)$ and MUC-1 $\left(r^{2}=0.9299 ; P=0.0001\right)$ (Supplementary Fig. 5B and C). While intracellular FC differed in response to mitotane and LXR $\alpha$ inhibition, baseline levels were similar for H295R and MUC-1 (Fig. 4C and D). Interestingly, intracellular lipid droplet storage of CE was undetectable in MUC-1, when compared to H295R (Fig. 4E, F, G and Supplementary Fig. 6A, B).

We next evaluated mitotane-induced cytotoxicity, in the presence and absence of LXR $\alpha$ inhibition, for each cell line under cholesterol-loaded cell culture conditions. Cholesterol

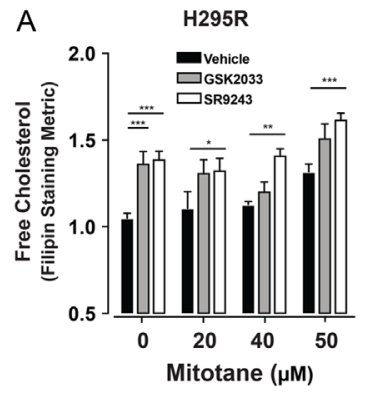

$\mathrm{F}$

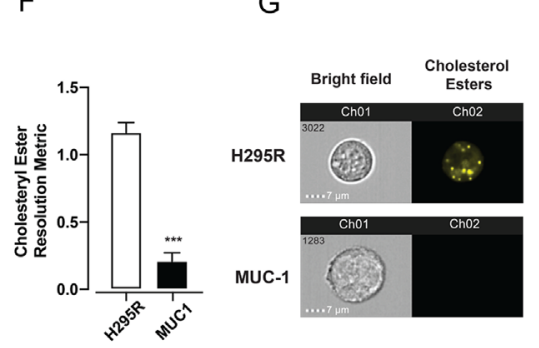

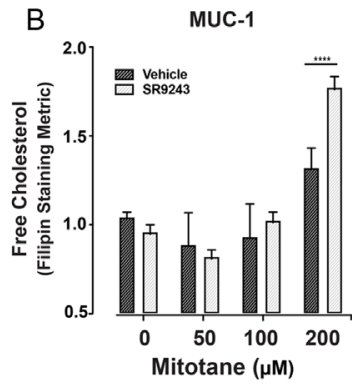

C
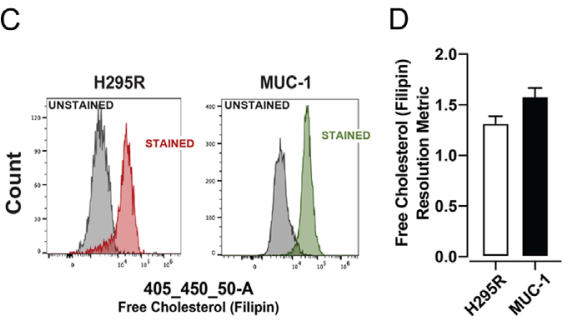

E

$\mathrm{H}$

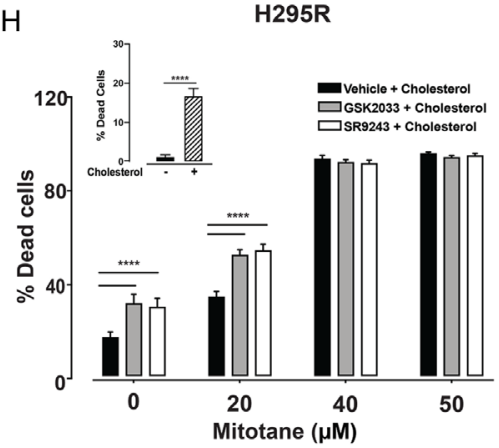

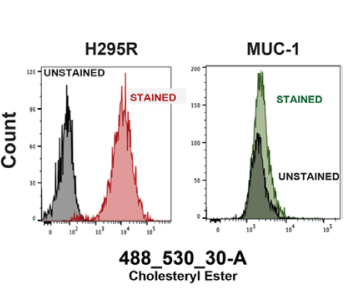

MUC-1

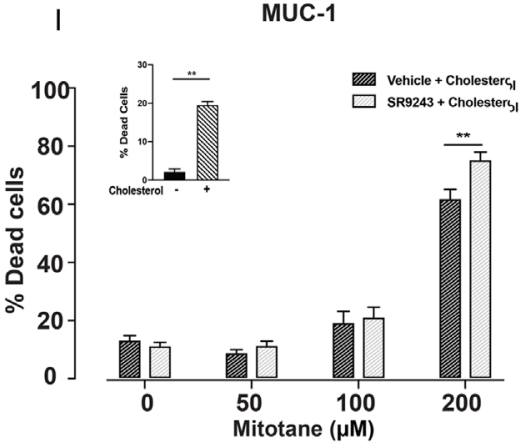

Figure 4

(A) Graphical representation of FC (filipin fluorescence), quantified by flow cytometry following combination treatments in H295R and (B) MUC-1. (C) Flow cytometry histograms demonstrating baseline FC (filipin fluorescence) levels in H295R and MUC-1 relative to respective unstained control. (D) Graphical representation of FC resolution metric in H295R and MUC-1. (E) Flow cytometry histograms demonstrating baseline cholesteryl ester fluorescence in H295R and MUC-1 relative to respective unstained control. (F) Graphical representation of cholesteryl ester resolution metric in H295R and MUC-1 cells. (G) Representative images (60x) of H295R and MUC-1 of brightfield and cholesteryl ester fluorescence captured via Amnis ImageStream ${ }^{\circledR}$ Imaging Flow Cytometry. (H) Graphical representation of percentage dead cells following combination treatments in the presence of cholesterol $(45 \mu \mathrm{g} / \mathrm{mL})$, inset graph indicating percentage death in the presence and absence of cholesterol in H295R and (I) in MUC-1. Data are represented as mean \pm S.E.M. $(n=3)$, statistical comparisons were performed using a two-tailed $t$-test or a two-way ANOVA followed by Tukey's post-hoc analysis. Statistical significance is denoted as

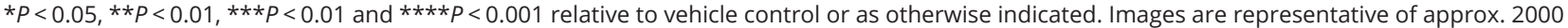
focused, single, live cells.

https://erc.bioscientifica.com https://doi.org/10.1530/ERC-20-0031 (c) 2020 The authors Published by Bioscientifica Ltd. Printed in Great Britain

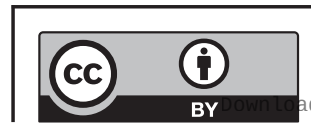

This work is licensed under a Creative Commons Attribution 4.0 International License. ded from Bioscientifica.com at 04/26/2023 09:25:21AM 
loading alone induced a moderate but significant increase in percentage cell death for both H295R (2\% (baseline) vs $15 \%$ (cholesterol loaded), $P<0.001)$ and MUC- $13 \%$ (baseline) vs $20 \%$ (cholesterol loaded), $P=0.0068$ ) when compared to non-loaded cell culture conditions. Treatment with each LXR $\alpha$ inhibitor resulted in a two-fold increase in H295R cell death in cholesterol-loaded cells. When combined with mitotane, both pharmacological LXR $\alpha$ inhibitors demonstrated significantly higher cell death for subtherapeutic doses of mitotane, with maximally observed cell death at $40 \mu \mathrm{M}(12.4 \mathrm{mg} / \mathrm{L})$ (Fig. $4 \mathrm{H})$. Cholesterol loading of MUC-1 resulted in an increased cell death at $100 \mu \mathrm{M}$ and $200 \mu \mathrm{M}$ mitotane $(7 \%$ (baseline mitotane $100 \mu \mathrm{M})$ vs $19 \%$ (cholesterol-loaded mitotane $100 \mu \mathrm{M}$ ), $P<0.011$ ) and $200 \mu \mathrm{M}(46 \%$ (baseline mitotane $200 \mu \mathrm{M})$ vs $62 \%$ (cholesterol-loaded mitotane $200 \mu \mathrm{M}$ ), $P<0.003)$ ). The LXR $\alpha$ inverse agonist SR9243 only significantly increased cell death when combined with mitotane at $200 \mu \mathrm{M}$ (Fig. 4I).

SOAT1 expression was significantly reduced by mitotane at doses $<40 \mu \mathrm{M}$ in H295R (Supplementary Fig. 5D). However, SOAT1 expression was unaffected by LXR $\alpha$ inhibition alone in both cell lines (Supplementary Fig. $5 \mathrm{E}$ and $\mathrm{F}$ ), suggesting that intracellular FC is increasing due to the alternative mechanism of reduced efflux pump expression (Fig. 3).

\section{Discussion}

Adrenocortical carcinoma (ACC) has demonstrated resistance to most cytotoxic chemotherapeutic approaches, with mitotane representing the single best pharmacotherapeutic for disease control; however, with a limited therapeutic window. Recent work demonstrated the putative adrenotoxic mechanism of mitotane through inhibition of the enzyme SOAT1, resulting in intracellular FC accumulation and suggests SOAT1-specific inhibitors as stand-alone therapy or adjuncts to mitotane in the management of ACC (Sbiera et al. 2015, LaPensee et al. 2016). In the study presented herein, we explored LXR $\alpha /$ cholesterol efflux pathway and proposed this as a complementary mechanism to enhance toxic intracellular FC accumulation in ACC. We investigated these effects on two validated in vitro models of ACC: H295R cells which are mitotane-sensitive and MUC- 1 , a metastatic, mitotane-insensitive cell line (Hantel et al. 2016).

Transcellular cholesterol flux in steroidogenic cells, such as ACC, is central to cellular function and cholesterol provides the principle substrate for steroidogenesis. In steroidogenic cells intracellular cholesterol (1) is stored within lipid droplets following conversion to cholesteryl esters by SOAT1 (Cignarella et al. 2005, Dove et al. 2006); (2) provides a substrate for steroidogenesis following transfer to the mitochondrion via the STAR protein (Stocco \& Clark 1996) or (3) is removed from the cells by the cholesterol efflux pumps, ABCA1 or ABCG1 to circulating ApoA1 and $\mathrm{HDL}_{1}$, respectively (Kraemer 2007). Cholesterol efflux is tightly regulated by the oxysterol/LXR $\alpha$ system through conversion of surplus FC to oxysterols through the action of enzymes such as CYP27A1. In the adrenal, the role of LXR $\alpha$ and its ligand oxysterols are of key relevance in all of these processes. This was highlighted by Cummins et al. who demonstrated the contribution of oxysterol/LXR $\alpha$ to (1) regulate steroidogenesis, (2) control adrenocortical cholesterol metabolism and (3) act as a 'safety valve' through the ABCA1/ABCG1-mediated efflux pathway, to provide a basal protective mechanism in preventing free-cholesterol induced adrenal lipotoxicity (Cummins et al. 2006).

Our data show that pharmacological inhibition or functional blockade of LXR $\alpha$ significantly reduced cholesterol efflux pump expression (ABCA1 and $A B C G 1)$ and is accompanied by higher intracellular FC concentrations, ER stress, apoptosis and cell death markers. Using the combined therapeutic approach, the mitotanesensitive H295R underwent apoptosis and cell death at subtherapeutic mitotane concentrations. However, MUC-1, while combined mitotane/LXR $\alpha$ inhibition considerably enhanced the cytotoxic effect of mitotane alone, retained their resistance to pharmacologically acceptable mitotane concentrations below $200 \mu \mathrm{M}$. In both cell lines, higher intracellular FC levels were associated with increased cell death and when challenged with a cholesterolloaded extracellular environment, the cytotoxic effect of mitotane alone and in combination with LXR $\alpha$ inhibition was further enhanced. These findings support our overarching hypothesis and are also in line with the findings of other groups (Sbiera and La Pensee) who have investigated SOAT1 inhibition (Sbiera et al. 2015, LaPensee et al. 2016). While H295R were very sensitive to combined LXR $\alpha /$ mitotane treatment and MUC-1 demonstrated enhanced sensitivity to the combination at high mitotane doses, MUC-1 gave disappointing results in terms of a therapeutic strategy. However, when taken together, we believe our data convincingly support a role for LXR $\alpha$ and cholesterol storage/efflux in ACC cell adaptation and survival.

It is unclear why MUC-1 are insensitive to LXR $\alpha$ / mitotane treatment. MUC-1 were derived from a metastatic neck lesion in a young, mitotane-resistant patient and

This work is licensed under a Creative Commons Attribution 4.0 International License. 
for whom four cycles of combination chemotherapy were unsuccessful in limiting the extent disease spread. When we evaluated intracellular cholesterol in MUC-1, we demonstrated an almost complete absence of stored cholesteryl esters (CE) at baseline and even under cholesterol-loaded conditions (data not shown). In contrast, mitotane-sensitive H295R supported a rich CE store within their intracellular lipid droplets under baseline and cholesterol-loaded culture conditions. Yet, in spite of markedly different intracellular CE stores, intracellular FC was similar for both cell lines. The difference in intracellular cholesterol handling between MUC-1 and H295R is interesting, particularly in the context of the putative mechanism of mitotane activity through SOAT1. We did not perform a SOAT1 activity assay; however, the reduced storage of CE in MUC-1 in the presence of similar FC suggests low baseline SOAT1 activity, irrespective of the expression of this enzyme. This also suggests that, in contrast to H295R, MUC-1 favor alternative mechanism(s) of regulation and clearance of intracellular cholesterol, providing a possible escape mechanism from mitotane-induced lipotoxicity. Seidel et al. have described similar findings in relation to FC and CE handling in a strain of HAC15 with induced resistance to mitotane (Seidel et al. 2020). Detailed evaluation of lipid/cholesterol metabolism in ACC, using the full range of cell lines and banked tumour samples, is necessary to evaluate the significance for development of future therapeutic strategies.

In the presence of increasing FC accumulation, higher mitotane doses attenuated the inhibitory effect of LXR $\alpha$ blockade on cholesterol efflux pump expression in H295R. In our study, mitotane alone had no significant effect on either $A B C A 1$ or $A B C G 1$ expression. Sbeira et al. previously demonstrated a short-lived decrease in $A B C G 1$ which quickly increased back to baseline with prolonged therapy (Sbiera et al. 2015). It is therefore unlikely that this is a direct pharmacodynamic effect of mitotane. It is a possible secondary effect of intracellular FC accumulation which is a substrate for catalysis to $27 \mathrm{HC}$ by CYP27A1 and will compete with the LXR $\alpha$ antagonists. In line with this observation, we have also demonstrated that stimulating LXR $\alpha$ with $27 \mathrm{HC}$ reduces the therapeutic efficacy of mitotane. Whether or not this represents a mechanism whereby ACC cells can overcome long-term susceptibility to mitotane needs more detailed investigation.

The role of LXR $\alpha$ in supporting the cancer microenvironment and promoting cancer cell survival is established in other human cancer models
(Kim et al. 2018, Wang et al. 2019). Higher tumour grade and enhanced metastasis in breast cancer have been associated with higher LXR $\alpha$ expression and activation (Nelson et al. 2013). Work by Flaveny et al. also demonstrated that the LXR $\alpha$ inverse agonist SR9243 induced apoptosis across models of lung, colon and prostate cancer (Flaveny et al. 2015). Other work has demonstrated the potential for LXR $\alpha$ inhibition to induce lipotoxicity through FC accumulation (Schuster et al. 2002, Bradley et al. 2007).

We propose that, based on our date, the use of LXR $\alpha$ inhibitors can be translated into a therapeutic strategy for mitotane-sensitive ACC by adopting a complementary approach to one of mitotane's known mechanisms of action: intracellular FC-induced lipotoxicity. We show that enhanced FC accumulation within H295R in response to LXR $\alpha$ blockade increased the cytotoxicity of mitotane at half the usual minimum therapeutic dose. The main limitations to mitotane's clinical use are (1) no significant improvements in progression or recurrencefree survival of disease below $14 \mathrm{mg} / \mathrm{L}$ (Terzolo et al. 2013, Berruti et al. 2017) and (2) poor patient tolerability, with significant impact on quality of life and inability to continue therapy above $20 \mathrm{mg} / \mathrm{mL}$ (Haak et al. 1994). Recent data have suggested that adjunctive mitotane should continue indefinitely even in individuals with R0 resection without tumour recurrence (Berruti et al. 2017). Therefore, the development of strategies to facilitate the long-term tolerability of this drug is an important clinical consideration. In relation to mitotaneresistant disease, we demonstrated increased cell death for MUC-1 in response to combined mitotane and LXR $\alpha$ inhibition, but show that mitotane-resistance was not overcome. Therefore, while adopting this combination strategy offers promise in mitotane-sensitive disease and to enhance adjuvant mitotane, it is unlikely to be of benefit in disease that is mitotane resistant. However, the differences in cholesterol handling between mitotanesensitive and mitotane-resistant ACC cells demonstrate the merits of better understanding the adaptation of ACC cells to facilitate metastasis and cell survival. Finally, we propose that the selective induction of high cholesterol uptake or selective delivery of cholesterol to ACC cells as a combination therapy represents an interesting challenge for future translational research.

In summary, two cell lines representing some of the best validated human cell culture models of ACC, the mitotane-resistant metastatic MUC-1 cell line and the mitotane-sensitive H295R, representing the standard for early mechanistic/therapeutic investigation, were https://erc.bioscientifica.com https://doi.org/10.1530/ERC-20-0031
(C) 2020 The authors Published by Bioscientifica Ltd. Printed in Great Britain
This work is licensed under a Creative Commons Attribution 4.0 International License.

ded from Bioscientifica.com at 04/26/2023 09:25:21AM 
used to investigate LXR $\alpha$ inhibitors and mitotane's effect to induce adrenal cytotoxicity (Rainey et al. 1994, Bird et al. 1995, Wang \& Rainey 2012, Hantel et al. 2016). Our data suggest a complementary pathway to enhance mitotane-induced cytotoxicity by preventing FC efflux from ACC cells, mediated through blockade of the LXR $\alpha$ pathway and enhanced by cholesterol loading. Therefore, it is reasonable to conclude that the mitotaneLXR $\alpha$ inhibition combined therapeutic approach exploits separate but complementary and synergistic mechanisms to accumulate toxic levels of FC and to induce ACC cytotoxicity. The findings provide valuable mechanistic insights and an important backdrop to support further animal and pre-clinical studies of the effects of LXR $\alpha$ inhibition as a therapeutic target for ACC in mitotanesensitive disease. Of the two pharmacological inhibitors chosen for investigation, the inverse agonist SR9243 is well tolerated in animals and has a favorable toxicity profile (Flaveny et al. 2015, Wu et al. 2019). This drug therefore presents good translational feasibility in future in vivo studies. We also highlight the ongoing challenge of approaching effective strategies for drugresistant metastatic disease and the importance of better understanding cholesterol metabolism in ACC cells in this regard.

\section{Supplementary materials}

This is linked to the online version of the paper at https://doi.org/10.1530/ ERC-20-0031.

\section{Declaration of interest}

The authors declare that there is no conflict of interest that could be perceived as prejudicing the impartiality of the research reported.

\section{Funding}

K M W is supported by the Irish Research Council Government of Ireland Postgraduate Research Scholarship. K V C and E S are supported by the Wellcome Trust $(210755 / Z / 18 / Z)$ and $K V$ C is supported by the NIHR Cambridge Biomedical Centre. E R M is supported by a EPRSC-SFI LifETIME CDT postgraduate PhD research scholarship. $\mathrm{C} \mathrm{H}$ is supported by the Uniscientia Foundation (Keyword Tumor Model). This work is also supported by the Irish Endocrine Society Basic Science Research Grant and by the Postgraduate Scholarship Fund at the School of Medicine, NUI Galway.

\section{Acknowledgements}

The authors would like to thank Ms Coralie Mureau and Dr Mark Webber for their technical assistance at The Lambe Institute for Translational Research. The authors would also like to thank Dr Shirley Hanley, Dr Joana Cabral and Dr Dagmar Quandt at the NUI Galway Flow Cytometry Core Facility.

\section{References}

Berruti A, Grisanti S, Pulzer A, Claps M, Daffarar F, Loli P, Mannelli M, Boscaro M, Arvat E, Tiberio G, et al. 2017 Long-term outcomes of adjuvant mitotane therapy in patients with radically resected adrenocortical carcinoma. Journal of Clinical Endocrinology and Metabolism 102 1358-1365. (https://doi.org/10.1210/jc.2016-2894)

Bird IM, Mathis JM, Mason JI \& Rainey WE 1995 Ca(2+)-regulated expression of steroid hydroxylases in H295R human adrenocortical cells. Endocrinology 136 5677-5684. (https://doi.org/10.1210/ endo.136.12.7588323)

Bradley MN, Hong C, Chen M, Joseph SB, Wilpitz DC, Wang X, Lusis AJ, Collins A, Hseuh WA, Collins JL, et al. 2007 Ligand activation of LXR beta reverses atherosclerosis and cellular cholesterol overload in mice lacking LXR alpha and apoE. Journal of Clinical Investigation 117 2337-2346. (https://doi.org/10.1172/JCI31909)

Brando B \& Sommaruga E 1993 Nationwide quality control trial on lymphocyte immunophenotyping and flow cytometer performance in Italy. Cytometry 14 294-306. (https://doi.org/10.1002/ cyto.990140310)

Bruschi FV, Claudel T, Tardelli M, Starlinger P, Marra F \& Trauner M 2019 PNPLA3 I148M variant impairs liver X receptor signaling and cholesterol homeostasis in human hepatic stellate cells. Hepatology Communications 3 1191-1204. (https://doi.org/10.1002/hep4.1395)

Chen LD, Kushwaha RS, McGill HC, Rice KS \& Carey KD 1998 Effect of naturally reduced ovarian function on plasma lipoprotein and 27-hydroxycholesterol levels in baboons (Papio sp.). Atherosclerosis 136 89-98. (https://doi.org/10.1016/s0021-9150(97)00190-1)

Chou TC 2008 Preclinical versus clinical drug combination studies. Leukemia and Lymphoma 49 2059-2080. (https://doi. org/10.1080/10428190802353591)

Cignarella A, Engel T, Von Eckardstein A, Kratz M, Lorkowski S, Lueken A, Assmann G \& Cullen P 2005 Pharmacological regulation of cholesterol efflux in human monocyte-derived macrophages in the absence of exogenous cholesterol acceptors. Atherosclerosis 179 229-236. (https://doi.org/10.1016/j.atherosclerosis.2004.11.005)

Costet P, Luo Y, Wang N \& Tall AR 2000 Sterol-dependent transactivation of the $\mathrm{ABC} 1$ promoter by the liver $\mathrm{X}$ receptor/ retinoid X receptor. Journal of Biological Chemistry 275 28240-28245. (https://doi.org/10.1074/jbc.M003337200)

Cummins CL, Volle DH, Zhang Y, Mcdonald JG, Sion B, LefrancoisMartinez AM, Caira F, Veyssiere G, Mangelsdorf DJ \& Lobaccaro JM 2006 Liver X receptors regulate adrenal cholesterol balance. Journal of Clinical Investigation 116 1902-1912. (https://doi.org/10.1172/ JCI28400)

de Reynies A, Assie G, Rickman DS, Tissier F, Groussin L, Rene-Corail F, Dousset B, Bertagna X, Clauser E \& Bertherat J 2009 Gene expression profiling reveals a new classification of adrenocortical tumors and identifies molecular predictors of malignancy and survival. Journal of Clinical Oncology 27 1108-1115. (https://doi.org/10.1200/ JCO.2008.18.5678)

Di D, Wang Z, Liu Y, Luo G, Shi Y, Berggren-Soderlund M, NilssonEhle P, Zhang X \& Xu N 2012 ABCA1 upregulating apolipoproein M expression mediates via the RXR/LXR pathway in HepG2 cells. Biochemical and Biophysical Research Communications 421 152-156. (https://doi.org/10.1016/j.bbrc.2012.04.022)

Dove DE, Su YR, Swift LL, Linton MF \& Fazio S 2006 ACAT1 deficiency increases cholesterol synthesis in mouse peritoneal macrophages. Atherosclerosis 186 267-274. (https://doi.org/10.1016/j. atherosclerosis.2005.08.005)

Engel T, Kannenberg F, Fobker M, Nofer JR, Bode G, Lueken A, Assmann G \& Seedorf U 2007 Expression of ATP binding cassettetransporter ABCG1 prevents cell death by transporting cytotoxic 7beta-hydroxycholesterol. FEBS Letters 581 1673-1680. (https://doi. org/10.1016/j.febslet.2007.03.038) 
Fassnacht M, Kroiss M \& Allolio B 2013 Update in adrenocortical carcinoma. Journal of Clinical Endocrinology and Metabolism 98 4551-4564. (https://doi.org/10.1210/jc.2013-3020)

Fassnacht M, Dekkers OM, Else T, Baudin E, Berruti A, De Krijger RR, Haak HR, Mihai R, Assie G \& Terzolo M 2018 European Society of Endocrinology Clinical Practice Guidelines on the management of adrenocortical carcinoma in adults, in collaboration with the European Network for the study of adrenal tumors. European Journal of Endocrinology 179 G1-G46. (https://doi.org/10.1530/EJE-18-0608)

Fedorova OV, Zernetkina VI, Shilova VY, Grigorova YN, Juhasz O, Wei W, Marshall CA, Lakatta EG \& Bagrov AY 2015 Synthesis of an endogenous steroidal na pump inhibitor marinobufagenin, implicated in human cardiovascular diseases, is initiated by CYP27A1 via bile acid pathway. Circulation: Cardiovascular Genetics $\mathbf{8}$ 736-745. (https://doi.org/10.1161/CIRCGENETICS.115.001217)

Flaveny CA, Griffett K, El-Gendy Bel Bel-D, Kazantzis M, Sengupta M, Amelio AL, Chatterjee A, Walker J, Solt LA, Kamenecka TM, et al. 2015 Broad anti-tumor activity of a small molecule that selectively targets the Warburg effect and lipogenesis. Cancer Cell 28 42-56. (https://doi.org/10.1016/j.ccell.2015.05.007)

Fu X, Menke JG, Chen Y, Zhou G, Macnaul KL, Wright SD, Sparrow CP \& Lund EG 2001 27-Hydroxycholesterol is an endogenous ligand for liver X receptor in cholesterol-loaded cells. Journal of Biological Chemistry 276 38378-38387. (https://doi.org/10.1074/jbc. M105805200)

Griffett K \& Burris TP 2016 Promiscuous activity of the LXR antagonist GSK2033 in a mouse model of fatty liver disease. Biochemical and Biophysical Research Communications 479 424-428. (https://doi. org/10.1016/j.bbrc.2016.09.036)

Haak HR, Hermans J, Van De Velde CJ, Lentjes EG, Goslings BM, Fleuren GJ \& Krans HM 1994 Optimal treatment of adrenocortical carcinoma with mitotane: results in a consecutive series of 96 patients. British Journal of Cancer 69 947-951. (https://doi. org/10.1038/bjc.1994.183)

Hantel C, Shapiro I, Poli G, Chiapponi C, Bidlingmaier M, Reincke M, Luconi M, Jung S \& Beuschlein F 2016 Targeting heterogeneity of adrenocortical carcinoma: evaluation and extension of preclinical tumor models to improve clinical translation. Oncotarget 7 79292-79304. (https://doi.org/10.18632/oncotarget.12685)

Hassall DG \& Graham A 1995 Changes in free cholesterol content, measured by filipin fluorescence and flow cytometry, correlate with changes in cholesterol biosynthesis in THP-1 macrophages. Cytometry 21 352-362. (https://doi.org/10.1002/cyto.990210407)

Hermsen IG, Fassnacht M, Terzolo M, Houterman S, Den Hartigh J, Leboulleux S, Daffara F, Berruti A, Chadarevian R, Schlumberger M, et al. 2011 Plasma concentrations of o,p'DDD, o, $\mathrm{p}^{\prime} \mathrm{DDA}$, and $\mathrm{o}, \mathrm{p}^{\prime} \mathrm{DDE}$ as predictors of tumor response to mitotane in adrenocortical carcinoma: results of a retrospective ENS@T multicenter study. Journal of Clinical Endocrinology and Metabolism 96 1844-1851. (https://doi.org/10.1210/jc.2010-2676)

Hescot S, Slama A, Lombes A, Paci A, Remy H, Leboulleux S, Chadarevian R, Trabado S, Amazit L, Young J, et al. 2013 Mitotane alters mitochondrial respiratory chain activity by inducing cytochrome c oxidase defect in human adrenocortical cells. EndocrineRelated Cancer 20 371-381. (https://doi.org/10.1530/ERC-12-0368)

Hsieh K, Lee YK, Londos C, Raaka BM, Dalen KT \& Kimmel AR 2012 Perilipin family members preferentially sequester to either triacylglycerol-specific or cholesteryl-ester-specific intracellular lipid storage droplets. Journal of Cell Science 125 4067-4076. (https://doi. org/10.1242/jcs.104943)

Hu X, Li S, Wu J, Xia C \& Lala DS 2003 Liver X receptors interact with corepressors to regulate gene expression. Molecular Endocrinology 17 1019-1026. (https://doi.org/10.1210/me.2002-0399)

Huuskonen J, Fielding PE \& Fielding CJ 2004 Role of p160 coactivator complex in the activation of liver $\mathrm{X}$ receptor. Arteriosclerosis,
Thrombosis, and Vascular Biology 24 703-708. (https://doi. org/10.1161/01.ATV.0000121202.72593.da)

Janowski BA, Willy PJ, Devi TR, Falck JR \& Mangelsdorf DJ 1996 An oxysterol signalling pathway mediated by the nuclear receptor LXR alpha. Nature 383 728-731. (https://doi.org/10.1038/383728a0)

Kennedy MA, Barrera GC, Nakamura K, Baldan A, Tarr P, Fishbein MC, Frank J, Francone OL \& Edwards PA 2005 ABCG1 has a critical role in mediating cholesterol efflux to HDL and preventing cellular lipid accumulation. Cell Metabolism 1 121-131. (https://doi.org/10.1016/j. cmet.2005.01.002)

Kerkhofs TM, Baudin E, Terzolo M, Allolio B, Chadarevian R, Mueller HH, Skogseid B, Leboulleux S, Mantero F, Haak HR, et al. 2013 Comparison of two mitotane starting dose regimens in patients with advanced adrenocortical carcinoma. Journal of Clinical Endocrinology and Metabolism 98 4759-4767. (https://doi. org/10.1210/jc.2013-2281)

Kim S, Lee M, Dhanasekaran DN \& Song YS 2018 Activation of LXRa/ beta by cholesterol in malignant ascites promotes chemoresistance in ovarian cancer. BMC Cancer 18 1232. (https://doi.org/10.1186/ s12885-018-5152-5)

Kraemer FB 2007 Adrenal cholesterol utilization. Molecular and Cellular Endocrinology 265-266 42-45. (https://doi.org/10.1016/j. mce.2006.12.001)

Lapensee CR, Mann JE, Rainey WE, Crudo V, Hunt 3rd SW \& Hammer GD 2016 ATR-101, a selective and potent inhibitor of acylCoA acyltransferase 1, induces apoptosis in H295R adrenocortical cells and in the adrenal cortex of dogs. Endocrinology 157 1775-1788. (https://doi.org/10.1210/en.2015-2052)

Lehmann TP, Wrzesinski T \& Jagodzinski PP 2013 The effect of mitotane on viability, steroidogenesis and gene expression in NCIH295R adrenocortical cells. Molecular Medicine Reports 7 893-900. (https:// doi.org/10.3892/mmr.2012.1244)

Libe R 2019 Clinical and molecular prognostic factors in adrenocortical carcinoma. Minerva Endocrinologica 44 58-69. (https://doi. org/10.23736/S0391-1977.18.02900-0)

Montgomery DA \& Welbourn RB 1965 Adrenocortical carcinoma treated with O,P'-Ddd. BMJ 1 1356-1358. (https://doi.org/10.1136/ bmj.1.5446.1356)

Nelson ER, Wardell SE, Jasper JS, Park S, Suchindran S, Howe MK, Carver NJ, Pillai RV, Sullivan PM, Sondhi V, et al. 2013 27-Hydroxycholesterol links hypercholesterolemia and breast cancer pathophysiology. Science 342 1094-1098. (https://doi.org/10.1126/ science.1241908)

Nilsson M, Stulnig TM, Lin CY, Yeo AL, Nowotny P, Liu ET \& Steffensen KR 2007 Liver X receptors regulate adrenal steroidogenesis and hypothalamic-pituitary-adrenal feedback. Molecular Endocrinology 21 126-137. (https://doi.org/10.1210/me.2006-0187)

Phelan CA, Weaver JM, Steger DJ, Joshi S, Maslany JT, Collins JL, Zuercher WJ, Willson TM, Walker M, Jaye M, et al. 2008 Selective partial agonism of liver $\mathrm{X}$ receptor alpha is related to differential corepressor recruitment. Molecular Endocrinology 22 2241-2249. (https://doi.org/10.1210/me.2008-0041)

Poli G, Guasti D, Rapizzi E, Fucci R, Canu L, Bandini A, Cini N, Bani D, Mannelli M \& Luconi M 2013 Morphofunctional effects of mitotane on mitochondria in human adrenocortical cancer cells. EndocrineRelated Cancer 20 537-550. (https://doi.org/10.1530/ERC-13-0150)

Pommier RF \& Brennan MF 1992 An eleven-year experience with adrenocortical carcinoma. Surgery 112 963-970; discussion 970-971.

Rainey WE, Bird IM \& Mason JI 1994 The NCI-H295 cell line: a pluripotent model for human adrenocortical studies. Molecular and Cellular Endocrinology 100 45-50. (https://doi.org/10.1016/03037207(94)90277-1)

Sbiera S, Leich E, Liebisch G, Sbiera I, Schirbel A, Wiemer L, Matysik S, Eckhardt C, Gardill F, Gehl A, et al. 2015 Mitotane inhibits sterol-Oacyl transferase 1 triggering lipid-mediated endoplasmic reticulum https://erc.bioscientifica.com https://doi.org/10.1530/ERC-20-0031 (c) 2020 The authors Published by Bioscientifica Ltd. Printed in Great Britain
This work is licensed under a Creative Commons Attribution 4.0 International License. ded from Bioscientifica.com at 04/26/2023 09:25:21AM 
stress and apoptosis in adrenocortical carcinoma cells. Endocrinology 156 3895-3908. (https://doi.org/10.1210/en.2015-1367)

Schuster GU, Parini P, Wang L, Alberti S, Steffensen KR, Hansson GK, Angelin B \& Gustafsson JA 2002 Accumulation of foam cells in liver $\mathrm{X}$ receptor-deficient mice. Circulation 106 1147-1153. (https://doi. org/10.1161/01.cir.0000026802.79202.96)

Seidel E, Walenda G, Messerschmidt C, Obermayer B, Peitzsch M, Wallace PW, Bahethi R, Yoo T, Choi M, Schrade P, et al. 2020 Generation and characterization of a mitotane-resistant adrenocortical cell line. Endocrine Connections 9 122-134. (https:// doi.org/10.1530/EC-19-0510)

Stocco DM \& Clark BJ 1996 Regulation of the acute production of steroids in steroidogenic cells. Endocrine Reviews 17 221-244. (https://doi.org/10.1210/edrv-17-3-221)

Terzolo M, Angeli A, Fassnacht M, Daffara F, Tauchmanova L, Conton PA, Rossetto R, Buci L, Sperone P, Grossrubatscher E, et al. 2007 Adjuvant mitotane treatment for adrenocortical carcinoma. New England Journal of Medicine 356 2372-2380. (https://doi. org/10.1056/NEJMoa063360)

Terzolo M, Baudin AE, Ardito A, Kroiss M, Leboulleux S, Daffara F, Perotti P, Feelders RA, Devries JH, Zaggia B, et al. 2013 Mitotane levels predict the outcome of patients with adrenocortical carcinoma treated adjuvantly following radical resection. European Journal of Endocrinology 169 263-270. (https://doi.org/10.1530/EJE-13-0242)

Wang T \& Rainey WE Human adrenocortical carcinoma cell lines 2012 Molecular and Cellular Endocrinology 351 58-65. (https://doi. org/10.1016/j.mce.2011.08.041)

Wang X, Collins HL, Ranalletta M, Fuki IV, Billheimer JT, Rothblat GH, Tall AR \& Rader DJ 2007 Macrophage ABCA1 and ABCG1, but not SR-BI, promote macrophage reverse cholesterol transport in vivo. Journal of Clinical Investigation 117 2216-2224. (https://doi. org/10.1172/JCI32057)

Wang K, Xu T, Ruan H, Xiao H, Liu J, Song Z, Cao Q, Bao L, Liu D, Wang C, et al. 2019 LXRalpha promotes cell metastasis by regulating the NLRP3 inflammasome in renal cell carcinoma. Cell Death and Disease 10 159. (https://doi.org/10.1038/s41419-019-1345-3)

Willy PJ, Umesono K, Ong ES, Evans RM, Heyman RA \& Mangelsdorf DJ 1995 LXR, a nuclear receptor that defines a distinct retinoid response pathway. Genes and Development 9 1033-1045. (https://doi. org/10.1101/gad.9.9.1033)

Wu G, Wang Q, Xu Y, Li J, Zhang H, Qi G \& Xia Q 2019 Targeting the transcription factor receptor LXR to treat clear cell renal cell carcinoma: agonist or inverse agonist? Cell Death and Disease 10416. (https://doi.org/10.1038/s41419-019-1654-6)

Received in final form 4 April 2020

Accepted 9 April 2020

Accepted Manuscript published online 9 April 2020 (c) 2020 The authors Published by Bioscientifica Ltd. Printed in Great Britain
This work is licensed under a Creative Commons Attribution 4.0 International License.

ded from Bioscientifica.com at 04/26/2023 09:25:21AM 